\title{
Crescimento vegetativo sazonal do cafeeiro e sua relação com fotoperíodo, frutificação, resistência estomática e fotossíntese
}

\author{
José Augusto Teixeira do Amaral(1), Alemar Braga Rena ${ }^{(2)}$ e José Francisco Teixeira do Amaral(1)
}

\begin{abstract}
(1)Universidade Federal do Espírito Santo, Centro de Ciências Agrárias, Dep. de Fitotecnia, Alto Universitário, s/no, Caixa Postal 16, CEP 29500-000 Alegre, ES. E-mail: jata@cca.ufes.br jfamaral@cca.ufes.br (2)Universidade Federal de Viçosa, Dep. de Biologia Vegetal, Av. PH Rolfs, s/no, CEP 36571-000 Viçosa, MG. E-mail: abrena41@hotmail.com
\end{abstract}

Resumo - O objetivo deste trabalho foi avaliar as flutuações sazonais do crescimento vegetativo do cafeeiro (Coffea arabica L.) e suas relações com o fotoperíodo, a remoção dos frutos, a fotossíntese e a resistência estomática. Os tratamentos foram constituídos por dois regimes fotoperiódicos - natural e estendido para 14 horas - em plantas com frutos e sem frutos. O crescimento de ramos e da área foliar decresceu a partir de meados de março, atingindo taxas mínimas nos meses de maio e junho, quando foram registradas as menores temperaturas. Esse modelo de crescimento não foi modificado pela extensão do fotoperíodo para 14 horas, nem pela remoção dos frutos, ainda que os cafeeiros sem frutos exibissem maiores taxas de crescimento dessas variáveis (ramo e área foliar). Não foi observada diferença significativa na fotossíntese potencial decorrente da presença de frutos, nem a extensão do fotoperíodo afetou taxas fotossintéticas. As taxas fotossintéticas potenciais não explicam os declínios do crescimento vegetativo, mas a temperatura mínima do ar correlacionou-se com as quedas do crescimento. A resistência estomática às $14 \mathrm{~h}$ apresentou valores relativamente elevados, de meados de março a início de maio, coincidindo com elevadas quedas no crescimento de ramos e da área foliar. O declínio inicial no crescimento vegetativo pode estar associado a temperaturas em torno de $14^{\circ} \mathrm{C}$.

Termos para indexação: Coffea arabica, temperatura, curva de crescimento.

\section{Seasonal vegetative growth of the coffee plant and its relationship with the photoperiod, fructification, stomatic resistance and photosynthesis}

\begin{abstract}
The objective of this work was to evaluate seasonal variations in vegetative growth in the coffee plant (Coffea arabica L.), as well as their relationships with photoperiod, fruits removal, photosynthesis and stomatic resistance. The growth of the branches and leaf area decreased from the middle of March on, reaching the lowest rates in May and June, when lowest air temperatures were registered. This growth model was not modified neither by extending the photoperiod up to 14 hours, nor by the removal of the fruits, even though fruitless coffee plants exhibited higher growth rates for branches and leaf areas. No significant difference was observed in the potential photosynthesis depending on the presence of fruits, and the extension of the photoperiod did not affect photosynthetic rates. Potential photosynthetic rates do not explain the decreases in growth. The minimum air temperature was associated to declines in the growth. At 14h, the stomatic resistance assumed relatively high values during the period from the middle of March to the beginning of May, so coinciding with drastic fall in the branch growth and leaf area gain. The initial decline in the vegetative growth can be associated to temperatures around $14^{\circ} \mathrm{C}$.
\end{abstract}

Index terms: Coffea arabica, temperature, photosynthesis, curves of growth.

\section{Introdução}

A periodicidade estacional do crescimento vegetativo do cafeeiro tem sido estudada em várias regiões cafeeiras do mundo, podendo ser muitas as causas para explicar o fenômeno (Barros \& Maestri, 1974; Maestri \& Barros, 1977; Rena \& Maestri, 1989; Barros et al.,
1997; Da Matta et al., 1997, 1999; Mota et al., 1997; Silva et al., 2004). Em regiões cafeeiras de latitudes elevadas, a fase de crescimento reduzido coincide com as épocas secas, frias e de fotoperíodos curtos (Rena \& Maestri, 1986, 1987).

Em Viçosa, MG (2045'S; altitude, 650 m), a similaridade entre os padrões de crescimento de plantas 
irrigadas e não irrigadas, bem como a retomada do crescimento antes do início das chuvas, permite concluir que a precipitação pluvial não explica a transição do crescimento ativo ao crescimento reduzido (Barros \& Maestri, 1974; Mota et al., 1997).

Segundo Sylvain (1958), o crescimento vegetativo do cafeeiro é complexo, e a periodicidade estacional pode ser atribuída a diversos fatores, tais como a lixiviação de nitrato pelas chuvas, competição dos frutos por fotoassimilados, menor intensidade de luz devido à nebulosidade e baixas temperaturas. Todavia, adubações com nitrogênio suplementar (nitrato ou uréia) no inverno, em plantas de café irrigadas, em Viçosa, não evitaram as quedas no crescimento de ramos e de folhas (Da Matta et al., 1999). Em Viçosa, onde a fase ativa do crescimento vegetativo e o crescimento reprodutivo ocorrem simultaneamente, os padrões de crescimento de ramos e de ganho de área foliar foram ligeiramente alterados pela remoção dos frutos, e as taxas de crescimento aumentaram significativamente nas plantas sem frutos (Mota et al., 1997; Amaral et al., 2001). Em Chinchiná, Colômbia, a insolação não esteve associada às quedas nas taxas de crescimento do café (Castillo Zapata, 1957).

Trabalhos pioneiros conduzidos por Franco (1940) indicaram que o cafeeiro apresenta características de planta de dia curto. Desde então, alguns autores têm confirmado esse comportamento (Piringer \& Borthwick, 1955; Went, 1957). Piringer \& Borthwick (1955) submeteram plantas jovens de C. arabica L. cv. Naranjos $\mathrm{T}_{2} \mathrm{P}_{3}$ 4-209 e C. arabica L. cv. Bourbon Vermelho à interrupção do período noturno com períodos de luz de três horas, ou a fotoperíodos variáveis, demonstrando que a iniciação floral ocorreu apenas em fotoperíodo de 13 horas ou menos. Went (1957) também trabalhou com plantas jovens de C. arabica L. cv. Bourbon, com exposição das plantas a fotoperíodos de 8, 16 e 24 horas, em conjugação com variações de temperaturas diurna e noturna, verificando que a iniciação floral somente ocorreu sob fotoperíodos de oito horas, independentemente da temperatura. Em contraposição, maiores intensidades de crescimento vegetativo ocorrem em cafeeiros jovens em resposta à exposição das plantas a fotoperíodos mais longos (Franco, 1940; Piringer \& Borthwick, 1955; Went, 1957; Söndahl et al., 1972; Monaco et al., 1978).

Com cafeeiros adultos, em condições de campo, as evidências não são conclusivas quanto aos efeitos do fotoperíodo sobre o crescimento das plantas. Em experimentos no Quênia (1 ${ }^{\circ} 8$ 'S), Cannell (1972) modificou o fotoperíodo por 12, 10 e 8 meses; apenas no primeiro ensaio, os dias longos favoreceram o crescimento de ramos laterais (número e extensão dos entrenós). Mesmo assim, essas respostas foram pequenas comparadas às encontradas por Piringer \& Borthwick (1955) e por Went (1957) em plantas jovens de café.

Tem-se verificado, entretanto, que, em regiões cafeeiras de latitudes mais elevadas, maiores taxas de crescimento coincidem com épocas em que os dias são mais longos (Boss, 1958; Sylvain, 1958; Barros \& Maestri, 1974; Mota et al., 1997; Silva et al., 2004). Em uma análise comparativa entre os ciclos de crescimento de ramos plagiotrópicos em Turrialba $\left(9^{\circ} 58^{\prime} \mathrm{N}\right)$, com fatores do ambiente, Cannell (1972) considerou a possibilidade de árvores de café daquela região responderem às variações naturais do fotoperíodo. Sugestões semelhantes foram feitas por Barros \& Maestri (1974), quanto às condições de Viçosa (205'S). As maiores intensidades de crescimento dos ramos laterais e das folhas desenvolvidas nesses ramos, segundo esses autores, ocorrem em épocas em que a duração dos dias era maior que 12 horas, e as menores intensidades ocorrem quando o comprimento dos dias era em torno de 11 horas. Não obstante, Mota et al. (1997) indicaram que a extensão do fotoperíodo, a partir de abril, em plantas adultas de café irrigadas e não irrigadas, somente foi acompanhada de maior crescimento de ramos plagiotrópicos e da formação da área foliar, em plantas irrigadas, nas duas primeiras semanas desse mês.

O objetivo deste trabalho foi estudar as flutuações sazonais do crescimento vegetativo do cafeeiro e suas relações com fotoperíodo, frutificação, fotossíntese e resistência estomática, bem como avaliar as variações do crescimento com as flutuações da temperatura do ar.

\section{Material e Métodos}

O experimento foi conduzido em área experimental da Universidade Federal de Viçosa, em Viçosa, MG, situada a uma altitude de aproximadamente $650 \mathrm{~m}$, a $20^{\circ} 45^{\prime} \mathrm{S}$ e $42^{\circ} 15^{\prime} \mathrm{W}$. Utilizaram-se cafeeiros (Coffea arabica L.) da cultivar Catuaí Vermelho, linhagem LCH 2066-2-5-51, com aproximadamente oito anos, cultivados a pleno sol, no espaçamento de $3 \times 2 \mathrm{~m}$, com 
duas plantas por cova. As fileiras de plantas foram estabelecidas no sentido norte-sul.

A área onde foi conduzida a pesquisa apresenta topografia plana e o solo é classificado como Podzólico Vermelho-Amarelo câmbico, fase terraço (PVc), e textura argilosa.

O delineamento experimental foi em blocos completos ao acaso, com duas repetições, utilizando-se parcelas subdivididas. As parcelas foram constituídas por dois regimes fotoperiódicos (natural e estendido para 14 horas) e as subparcelas formadas por plantas com frutos e sem frutos. Nas subparcelas sem frutos, três meses antes do início do experimento, realizou-se a remoção dos frutos. O regime fotoperiódico foi controlado por meio de um relógio temporizador que acendia as lâmpadas diariamente das 17 às $19 \mathrm{~h}$ e das 5 às $7 \mathrm{~h}$. A extensão do fotoperíodo foi efetuada mediante lâmpadas incandescentes de $200 \mathrm{~W}$, posicionadas a $2 \mathrm{~m}$ da copa das plantas. As iluminâncias medidas no topo, meio e base das plantas foram iguais a 980, 340 e 150 lx, respectivamente. As fileiras dos cafeeiros mantidos sob fotoperíodo natural distaram, no mínimo, $10 \mathrm{~m}$ daquelas submetidas a fotoperíodo estendido. Além disso, a forma cônica dos projetores minimizou a dissipação de luz para os cafeeiros sob condições naturais.

Durante a fase experimental, os cafeeiros foram mantidos sem competição com ervas daninhas. O experimento foi irrigado regularmente por infiltração na projeção da copa das plantas, visando a manter o solo da área experimental próximo da capacidade de campo. A fertilização por cova foi realizada com 120 g de N, 24 g de $\mathrm{P}_{2} \mathrm{O}_{5}$ e 120 g de $\mathrm{K}_{2} \mathrm{O}$ em quatro aplicações, iniciadas seis meses antes do estudo. Em adição, foram feitas pulverizações com micronutrientes. O bicho-mineiro (Leucoptera coffeella) e a broca (Hypothenemus hampei) foram controlados com pulverizações com ethion e endosulfan, respectivamente.

Foram marcados 14 ramos plagiotrópicos primários, em cada subparcela, no terço superior da copa das plantas, sendo sete orientados para leste e sete para oeste. A área foliar (L) foi determinada segundo a equação $\mathrm{L}=0,667 \mathrm{X}$, em que a variável independente é a área do retângulo circunscrito na folha - maior comprimento multiplicado pela maior largura da lâmina foliar (Barros et al., 1973) -, a intervalos de aproximadamente dez dias. Simultaneamente, mediram-se os alongamentos dos ramos.
A temperatura e a umidade relativa do ar foram determinadas no próprio local do experimento por meio de termoigrógrafo Lambrecht, modelo 252.

A resistência difusiva estomática foi medida no terceiro par de folhas de ramos laterais dos lados leste e oeste do terço superior da copa, às 9 e às $14 \mathrm{~h}$, somente em cafeeiros sem frutos sob fotoperíodo normal, utilizando-se um porômetro de difusão com sensor horizontal, adaptado por Kanemasu et al. (1969), ajustado à superfície abaxial da folha.

A evolução de $\mathrm{O}_{2}$ fotossintético (fotossíntese potencial) foi quantificada no terceiro par de folhas de ramos laterais situados no terço superior da copa, mediante o uso do Monitor Biológico de Oxigênio Yellow Spring, modelo 53, segundo o método descrito por Jones \& Osmond (1973), modificado conforme resultados alcançados por Alves (1985). Logo depois da remoção das folhas, às $9 \mathrm{~h}$, os pecíolos eram imersos em água. O conjunto era transferido para o laboratório, para determinações da fotossíntese, no máximo, em 30 minutos.

\section{Resultados e Discussão}

As taxas de crescimento de ramos (Figura 1) e da área foliar (Figura 2) de todos os tratamentos começaram a diminuir em meados de março, atingindo os me-

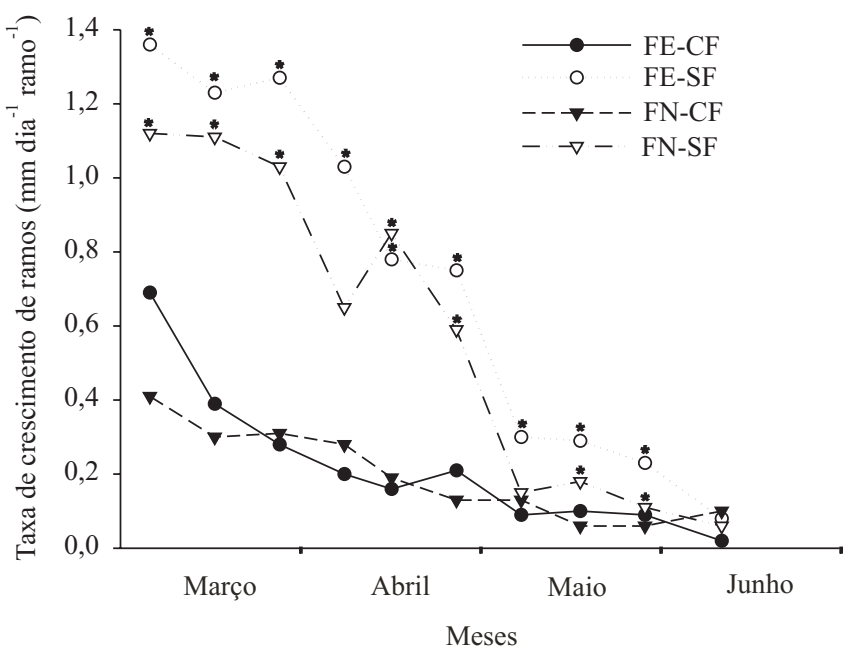

Figura 1. Taxa de crescimento de ramos plagiotrópicos primários de cafeeiros submetidos a fotoperíodo estendido (FE) e fotoperíodo normal (FN), com fruto (CF) e sem fruto (SF). Os asteriscos indicam diferenças significativas em função da presença ou ausência de frutos em cada regime fotoperiódico, pelo teste de Tukey a 5\% de probabilidade. 
nores valores em maio e junho. Não houve diferença entre os padrões de crescimento dos ramos plagiotrópicos primários e das folhas. Esse comportamento do crescimento vegetativo do cafeeiro foi semelhante ao reportado por Barros \& Maestri (1974) em Viçosa.

Independentemente da presença de frutos, o crescimento de ramos e de folhas não foi modificado pela extensão do fotoperíodo para 14 horas a partir do início de março (Figuras 1 e 2), à semelhança dos resultados apresentados por Mota et al. (1997), os quais notaram que a extensão do fotoperíodo somente retardou as quedas de crescimento nas plantas irrigadas, nas duas primeiras semanas do mês de abril. Parece que o crescimento vegetativo de cafeeiros adultos não responde às variações naturais do fotoperíodo. Cannell (1972) modificou o fotoperíodo curto natural em Ruiru, no Quênia, com lâmpadas incandescentes de filamento de tungstênio, em três experimentos distintos, por 12, 10 e 8 meses, respectivamente, utilizando C. arabica L., cultivares SL28 e SL34. Segundo o autor, somente no primeiro ensaio - extensão do fotoperíodo para 16 horas ou interrompendo o período noturno com luz de 3 horas de duração -, os dias longos favoreceram ligeiramente o crescimento de ramos laterais. Para o autor, essas respostas foram insignificantes em relação aos resultados alcançados por Piringer \& Borthwick (1955) e por Went (1957) com plantas jovens de café. Cannell (1972) também verificou que a interrupção do período

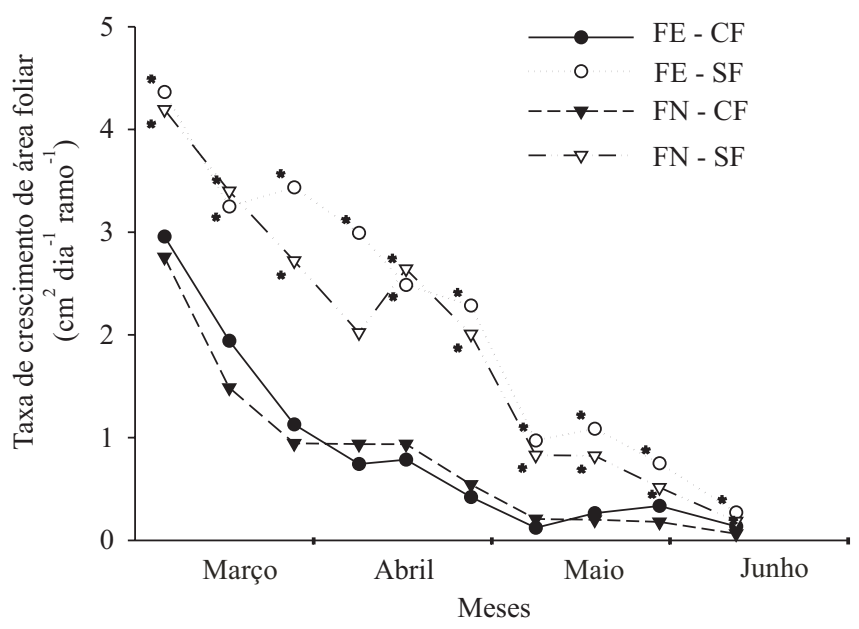

Figura 2. Taxa de crescimento de área foliar de ramos plagiotrópicos primários de cafeeiros submetidos a fotoperíodo estendido (FE) e fotoperíodo normal (FN), com fruto (CF) e sem fruto (SF). Os asteriscos indicam diferenças significativas em função da presença ou ausência de frutos em cada regime fotoperiódico, pelo teste de Tukey a 5\% de probabilidade. noturno por 3 horas ou 15 minutos com luz de intensidades diferentes (60 ou $200 \mathrm{~W}$ ) não afetou o desenvolvimento vegetativo das plantas, nem a floração.

Os fenômenos fotomorfogênicos são complexos, sendo a maioria deles mediada por fitocromos, cujas apoproteínas são codificadas por uma família multigênica, gerando dois tipos principais de fitocromos com propriedades distintas. Cada resposta das plantas é regulada por um fitocromo específico ou por interação entre fitocromos específicos, que exercem uma variedade de respostas nas plantas em função da quantidade, duração e do espectro de ação da luz (Taiz \& Zeiger, 2002). Não se pode descartar a possibilidade de que, em condições naturais, o sinal fotoperiódico possa ser perturbado, modulado ou substituído por outros fatores (Rena \& Maestri, 1986).

As taxas de crescimento de ramos primários (Figura 1) e da área foliar (Figura 2) foram significativamente maiores em plantas sem frutos em toda fase estudada. Os frutos constituem os drenos mais fortes das plantas, podendo alocar assimilados das folhas vizinhas e mesmo das regiões mais distantes na planta (Cannell, 1970). Por conseguinte, a competição imposta durante o desenvolvimento dos frutos pode ser um fator de restrição ao crescimento vegetativo, em virtude da maior mobilização de assimilados para os órgãos reprodutivos, em detrimento dos órgãos vegetativos (Cannell \& Huxley, 1970; Cannell, 1971). Outros autores também mostraram que o padrão sazonal de crescimento vegetativo não é modificado pela remoção dos frutos, ainda que as plantas sem frutos possam apresentar maiores taxas de crescimento (Boss, 1958; Mota et al., 1997; Libardi et al., 1998; Amaral et al., 2001).

Em geral, o crescimento dos ramos e das folhas acompanhou as curvas de temperatura, sobretudo as de temperaturas média e mínima (Figura 3). Entretanto, a média das temperaturas parece não ser suficiente para explicar os decréscimos no crescimento. De acordo com Alègre (1959), a temperatura média favorável ao crescimento do cafeeiro situa-se entre 16 e $23^{\circ} \mathrm{C}$, com um ótimo de 18 a $21^{\circ} \mathrm{C}$. Observa-se que, no começo da queda do crescimento (Figuras 1 e 2), as médias das temperaturas (Figura 3) eram próximas dos valores referidos por Alègre (1959). Desse modo, a média das temperaturas não explica satisfatoriamente esse fenômeno. Já a oscilação da temperatura mínima apresentou estreita relação com a flutuação no crescimento. Por isso, em meados de março, a média semanal das temperaturas mínimas foi de $15,1^{\circ} \mathrm{C}$ 
(Figura 3), estando abaixo da faixa admitida como ótima por Alègre (1959). Essa média das temperaturas mínimas foi constituída por temperaturas mínimas diárias relativamente baixas nos dias $12\left(14,5^{\circ} \mathrm{C}\right)$ e $13\left(13,5^{\circ} \mathrm{C}\right)$ de março.

É possível que os declínios iniciais no crescimento possam estar associados a temperaturas relativamente baixas, ocorridas esporadicamente, ainda que a média das temperaturas no período correspondente seja aparentemente adequada ao crescimento. Na terceira semana de março, a média das temperaturas mínimas foi $16,2^{\circ} \mathrm{C}$ (Figura 3) e, nos dias 21 e 22 desse mês, ocorreram temperaturas mínimas de 13,0 e $13,1^{\circ} \mathrm{C}$, respectivamente. $\mathrm{O}$ crescimento continuou a cair na primeira quinzena de abril (Figuras 1 e 2), época em que a média das temperaturas mínimas do ar não foi aparentemente desfavorável (Figura 3), mas entre os dias 9 e 13 de abril ocorreram temperaturas mínimas entre 13,5 e $15,0^{\circ} \mathrm{C}$. Maiores reduções no crescimento (Figuras 1 e 2) coincidiram com menores médias da temperatura mínima (Figura 3).

Entre os fatores limitantes relatados por Sylvain (1958), a queda da temperatura mínima foi o que melhor apresentou relação com o crescimento neste estudo. No Zimbábue, onde as oscilações climáticas são semelhantes às de Viçosa, o crescimento é mínimo de abril a setembro, período em que são registradas médias de temperaturas inferiores a $15^{\circ} \mathrm{C}$ (Clowes \& Wilson, 1974). Na região central da Colômbia, temperaturas noturnas abaixo de $15^{\circ} \mathrm{C}$ são freqüentes nas épocas de menor atividade vegetativa do café (Castillo Zapata, 1957). Vários trabalhos também constataram que o crescimento do cafeeiro é lento nos meses mais frios do ano (Rayner, 1946; Cooil, 1954; Suarez De Castro \&

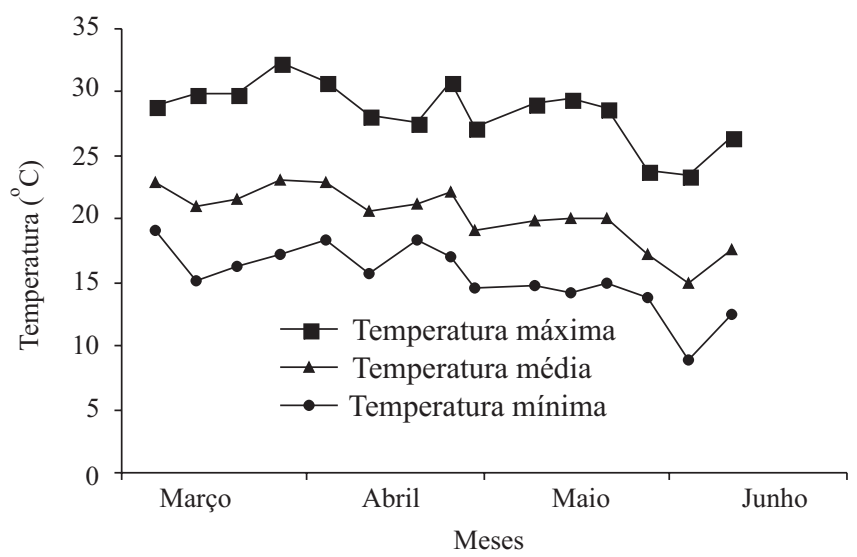

Figura 3. Médias semanais das temperaturas máxima, média e mínima da atmosfera local.
Rodriguez, 1956; Castillo Zapata, 1957; Boss, 1958; Barros et al., 1997; Mota et al., 1997; Libardi et al., 1998; Da Matta et al., 1999; Silva et al., 2004).

A resistência difusiva estomática foi menor pela manhã que à tarde, assumindo valores relativamente elevados à tarde, de meados de março ao início de maio (Figura 4), coincidindo com quedas drásticas no crescimento de ramos (Figura 1) e na expansão da área foliar (Figura 2). Aumentos na resistência estomática durante a época fria em Viçosa também foram relatados por outros pesquisadores. Maestri \& Vieira (1958) constataram que, durante a época seca e fria em Viçosa, os estômatos do cafeeiro permaneceram praticamente fechados o dia todo, exceto durante algumas horas pela manhã, tanto em cafeeiros cultivados a pleno sol quanto à sombra de árvores, fato que os autores atribuíram ao baixo teor de umidade do solo. Barros et al. (1997), trabalhando com a mesma lavoura utilizada neste trabalho, constataram que baixos valores de déficit de pressão de vapor e alto potencial hídrico xilemático das folhas não estavam correlacionados com a elevação diária da resistência estomática em dias antecedidos por noites frias. Da Matta et al. (1997) observaram decréscimos pela

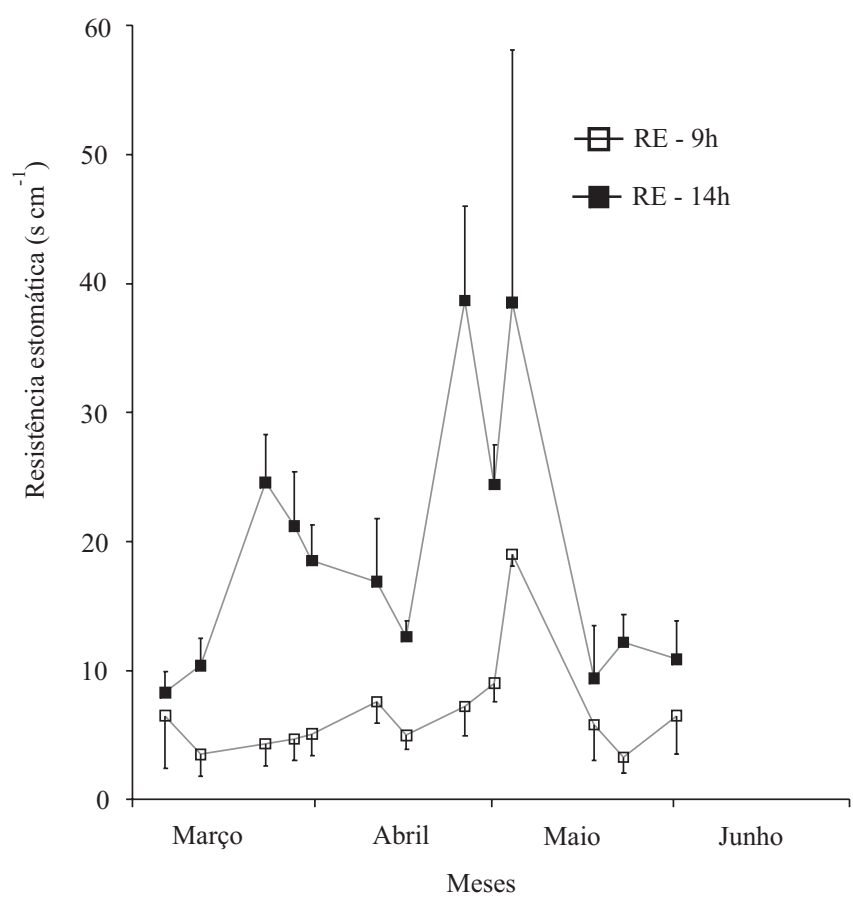

Figura 4. Resistência difusiva estomática de cafeeiros sem frutos, sob fotoperíodo normal, medida entre 9 e 10h (RE - 9h) e entre 14 e 15h (RE - 14h). Cada ponto representa a média de sete medições. As barras verticais representam os desviospadrão. 
manhã na condutância estomática na época fria, em relação ao verão, com mais intensidade em C. arabica L. cv. Catuaí que em C. canephora Pierre cv. Conilon.

Não foram observadas diferenças significativas na fotossíntese potencial em virtude da presença de frutos, nem a extensão do fotoperíodo afetou a taxa fotossintética (Figura 5). Ademais, as taxas fotossintéticas potenciais (Figura 5) não explicam os declínios no crescimento de ramos e de folhas, sugerindo que a diminuição do crescimento não está associada a maior resistência bioquímica da fotossíntese. Isto porque a fotossíntese só diminuiu no final de maio (Figura 5), quando o crescimento já se aproximava do mínimo (Figuras 1 e 2). Silva et al. (2004) também não encontraram relação de causa e efeito entre as depressões nas taxas fotossintéticas líquidas e as quedas no crescimento vegetativo durante o período de crescimento reduzido do cafeeiro, sugerindo que esses decréscimos ocorrem paralelamente.

As variações nas taxas fotossintéticas potenciais (Figura 5) acompanharam a curva de temperaturas mínimas (Figura 3). A fotossíntese líquida do cafeeiro também decresce a temperaturas relativamente baixas (Frischknecht et al., 1982; Bauer et al., 1985; Da Matta et al., 1997; Silva et al., 2004). Uma vez que os estômatos constituem as principais vias de trocas gasosa entre a folha e o meio, um aumento na resistência difusiva estomática pode ocasionar reduções na fotossíntese líquida. Todavia, Silva et al. (2004), estudando variações nas trocas gasosas do cafeeiro, constataram que as al-

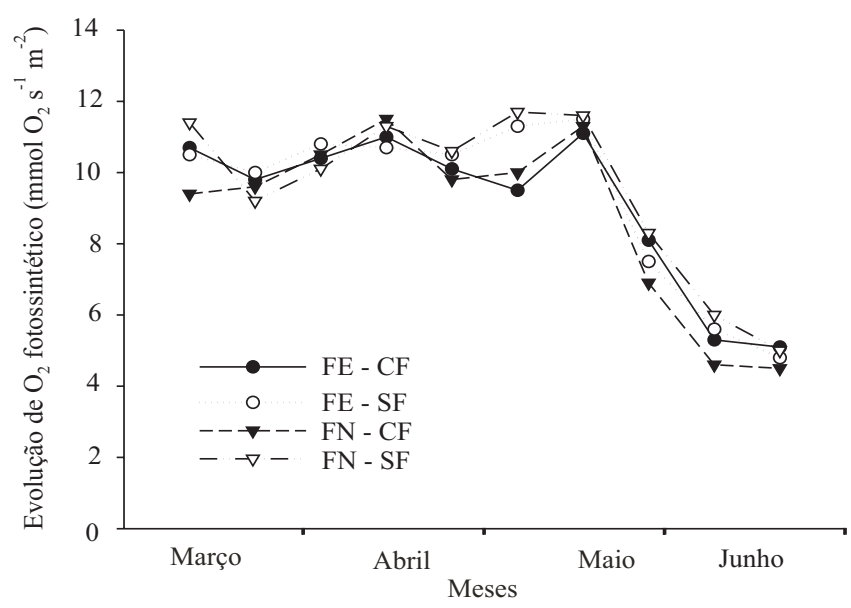

Figura 5. Fotossíntese potencial de cafeeiros submetidos a fotoperíodo estendido (FE) e fotoperíodo normal (FN), com fruto (CF) e sem fruto (SF). terações nas taxas fotossintéticas líquidas parecem ser devidas às limitações estomáticas apenas na fase de crescimento ativo (verão), sem nenhuma relação entre si no período de crescimento reduzido (inverno). Provavelmente as diminuições nas taxas fotossintéticas potenciais sejam devidas a resistências bioquímicas nos cloroplastídios provocadas por temperaturas do ar relativamente baixas.

As flutuações observadas nas taxas fotossintéticas potenciais (Figura 5) aparentemente não estão associadas às variações da resistência estomática (Figura 4), pois, de março a maio, ocorreram variações na abertura estomática, enquanto as taxas fotossintéticas ficaram aproximadamente estáveis. Além disso, a determinação polarográfica do oxigênio fotossintético em tiras foliares elimina o controle exercido pelos estômatos sobre a fotossíntese (Jones \& Osmond, 1973), indicando, também, provável controle não estomático ligado a resistências bioquímicas. Segundo Da Matta et al. (1997), o aumento no conteúdo de amido nas folhas do cafeeiro, durante o inverno, seria uma causa para a pronunciada inibição da fotossíntese potencial a baixas temperaturas. Os autores mantiveram folhas de cafeeiro não destacadas da planta no escuro por 96 horas, durante o inverno, de modo a reduzir o conteúdo de amido nas folhas à metade, constatando que as taxas fotossintéticas potenciais eram restauradas, depois das folhas destacadas serem colocadas em câmaras úmidas, com os pecíolos imersos em água, em temperaturas noturnas de $4,8,20$ ou $32^{\circ} \mathrm{C}$.

\section{Conclusões}

1. O padrão sazonal de crescimento de ramos e da área foliar não é modificado pelo aumento do fotoperíodo para 14 horas.

2. A remoção dos frutos não impede as quedas nas taxas de crescimento de ramos e das folhas, apesar de serem maiores em cafeeiros sem frutos.

3. As flutuações nas taxas fotossintéticas potenciais não explicam as variações no crescimento, e as diminuições ocorridas nessas taxas podem estar relacionadas com resistências bioquímicas nos cloroplastídios.

4. A elevação da resistência estomática à tarde coincide com as quedas drásticas no crescimento de ramos e de área foliar.

5. As quedas no crescimento vegetativo estão associadas com as oscilações da temperatura mínima do ar. 


\section{Referências}

ALÈGRE, C. Climats et caféiers d'Arabie. Agronomie Tropicale, v.14, p.23-58, 1959.

ALVES, J.D. Relação entre a redutase do nitrato e a fotossíntese no cafeeiro (Coffea arábica L.). 1985. 38p. Dissertação (Mestrado) - Universidade Federal de Viçosa, Viçosa.

AMARAL, J.A.T.; DA MATTA, F.M.; RENA, A.B. Effects of fruiting on the growth of Arabica coffee trees as related to carbohydrate and nitrogen status and to nitrate reductase activity. Revista Brasileira de Fisiologia Vegetal, v.13, p.66-74, 2001.

BARROS, R.S.; MAESTRI, M. Influência dos fatores climáticos sobre a periodicidade de crescimento vegetativo do café (Coffea arabica L.). Revista Ceres, v.21, p.268-279, 1974.

BARROS, R.S.; MAESTRI, M.; VIEIRA, M.; BRAGAFILHO, L.J. Determinação da área de folhas do café (Coffea arabica L. cv. Bourbon Amarelo). Revista Ceres, v.20, p.44-52, 1973.

BARROS, R.S.; MOTA, J.W.S.; DA MATTA, F.M.; MAESTRI, $\mathrm{M}$. Decline of vegetative growth in Coffea arabica L. in relation to leaf temperature, water potential and stomatal conductance. Field Crops Research, v.54, p.65-72, 1997.

BAUER, H.; WIERER, R.; HATHEWAY, W.H.; LARCHER, W. Photosynthesis of Coffea arabica after chilling. Physiologia Plantarum, v.64, p.449-454, 1985.

BOSS, M.L. Some environmental factors related to the growth cycle of Coffea arabica L. Proceedings of the Florida State Horticultural Society, v.71, p.327-332, 1958.

CANNELL, M.G.R. Contribution of carbohydrates from vegetative laterals of the growth of fruits on the bearing branches of Coffea arabica. Turrialba, v.20, p.15-19, 1970.

CANNELL, M.G.R. Photoperiodic response of mature trees of Arabica coffee. Turrialba, v.22, p.198-206, 1972.

CANNELL, M.G.R. Production and distribution of dry matter in trees of Coffea arabica L. in Kenya as affected by seasonal climatic differences and the presence of fruits. Annals of Applied Biology, v.67, p.99-120, 1971.

CANNELL, M.G.R.; HUXLEY, P.A. Seasonal patterns of growing and development of Arabica coffee in Kenya. Kenya Coffee, v.35, p.139-143, 1970.

CASTILLO ZAPATA, J. Observaciones sobre la relación del crecimiento del cafeto y temperatura, en condiciones de campo. Cenicafé, v.8, p.305-313, 1957.

CLOWES, M.S.-J.; WILSON, J.H. Physiological factors influencing irrigation management of coffee in Rhodesia. Rhodesian Agricultural Journal, v.71, p.53-55, 1974.

COOIL, B.J. Leaf composition in relation to growth and yield of coffee in Kona. Kona, Hawaii: Coffee Information Exchange, 1954. 13p.
DA MATTA, F.M.; AMARAL, J.A.T. do; RENA, A.B. Growth periodicity in trees of Coffea arabica L. in relation to nitrogen supply and nitrate reductase activity. Field Crops Research, v.60, p.223229, 1999.

DA MATTA, F.M.; MAESTRI, M.; MOSQUIM, P.R.; BARROS, R.S. Photosynthesis in coffee (Coffea arabica and C. canephora) as affected by winter and summer conditions. Plant Science, v.128, p.43-50, 1997.

FRANCO, C.M. Fotoperiodismo em cafeeiro (Coffea arabica L.). Revista do Instituto de Café, v.27, p.1586-1592, 1940.

FRISCHKNECHT, P.M.; ELLER, B.M.; BAUMANN, T.W. Purine alkaloid formation and $\mathrm{CO}_{2}$ gas exchange in dependence of development and of environmental factors in leaves of Coffea arabica L. Planta, v.156, p.295-301, 1982.

JONES, H.G.; OSMOND, C.B. Photosynthesis by thin leaf slices in solution. I. Properties of leaf slices and comparison with whole leaves. Australian Journal of Biological Sciences, v.26, p.15-24, 1973.

KANEMASU, E.T.; THURTELL, G.W.; TANNER, C.B. Design, calibration and field use of a stomatal diffusion porometer. Plant Physiology, v.44, p.881-885, 1969.

LIBARDI, V.C. de M.; AMARAL, J.A.T. do; AMARAL, J.F.T. do. Crescimento vegetativo sazonal do cafeeiro (Coffea canephora Pierre var. Conilon) no sul do Estado do Espírito Santo. Revista Brasileira de Agrometeorologia, v.6, p.23-28, 1998.

MAESTRI, M.; BARROS, R.S. Coffee. In: ALVIM, P. de T.; KOZLOWSKI, T.T. (Ed.). Ecophysiology of tropical crops. New York: Academic Press, 1977. p.249-278.

MAESTRI, M.; VIEIRA, C. Movimento de estômatos em café, sob condições naturais. Revista Ceres, v.10, p.324-331, 1958.

MÔNACO, L.C.; MEDINA FILHO, H.P.; SÖNDAHL, M.R.I.; LIMA, M.M.A. de. Efeitos de dias longos no crescimento e florescimento de cultivares de café. Bragantia, v.37, p.25-32, 1978.

MOTA, J.W.S.; DA MATA, F.M.; BARROS, R.S.; MAESTRI, M. Vegetative growth in Coffea arabica L. as affected by irrigation, daylength and fruiting. Tropical Ecology, v.38, p.73-79, 1997.

PIRINGER, A.A.; BORTHWICK, H.A. Photoperiodic responses of coffee. Turrialba, v.5, p.72-77, 1955.

RAYNER, R.W. Growth and bearing habits of Coffea arabica in Kenya and in Southern India. East African Agricultural and Forestry Journal, v.11, p.251-255, 1946.

RENA, A.B.; MAESTRI, M. Ecofisiologia do cafeeiro. In: CASTRO, P.R.C.; FERREIRA, S.O.; YAMADA, T. (Ed.). Ecofisiologia do cafeeiro. Piracicaba: Associação Brasileira para Pesquisa da Potassa e do Fosfato, 1987. p.119-147.

RENA, A.B.; MAESTRI, M. Fisiologia do cafeeiro. In: RENA, A.B.; MALAVOLTA, E.; ROCHA, M.; YAMADA, T. Cultura do 
cafeeiro: fatores que afetam a produtividade. Piracicaba: Potafos, 1986. p.13-85.

RENA, A.B.; MAESTRI, M. The vegetative growth of the coffee plant. Indian Coffee, v.53, p.19-23, 1989.

SILVA, E.A.; DA MATTA, F.M.; DUCATTI, C.; REGAZZI, A.J.; BARROS, R.S. Seasonal changes in vegetative growth and photosynthesis of Arabica coffee trees. Field Crops Research, v.89, p.349-357, 2004.

SÖNDAHL, M.R.I.; MÔNACO, L.C.; CARVALHO, A.; FAZUOLI, L.C. Efeito de dias longos em progênies de café, tratadas com benziladenina e giberelina. Ciência e Cultura, v.24, p.336, 1972.
SUAREZ DE CASTRO, F.; RODRÍGUEZ, A. Relación entre el crecimiento del cafeto y algunos factores climáticos. Chinchiná: Federación nacional de Cafeteros de Colombia, 1956. p.1-13. (Boletín técnico, 16).

SYLVAIN, P.G. El ciclo de crecimiento de Coffea arabica. Turrialba: Instituto Interamericano de Ciências Agrícolas, 1958. 17p.

TAIZ, L.; ZEIGER, E. Plant physiology. $3^{\text {rd }}$ ed. Sunderland: Sinauer Associates, 2002. 690p.

WENT, F.W. The experimental control of plant growth. New York: Ronald Press, 1957. 8v. (Chronica botanica, 17).

Recebido em 14 de janeiro de 2005 e aprovado em 29 de junho de 2005 